\title{
Apolipoprotein E genetic polymorphism, serum lipoprotein levels and breast cancer risk: A case-control study
}

\author{
GABRIELA HERRMANN CIBEIRA ${ }^{1}$, JULIANA GIACOMAZZI ${ }^{2,3}$, ERNESTINA AGUIAR ${ }^{3}$, SILVANA SCHNEIDER ${ }^{3}$, \\ BETINA ETTRICH ${ }^{4}$, CAROLINE ISOPPO DE SOUZA $^{4}$, SUZI CAMEY $^{5}$, MAIRA CALEFFI $^{6}$, \\ BERNARDETE WEBER ${ }^{7}$, PATRICIA ASHTON-PROLLA ${ }^{3,4}$ and EMILIO HIDEYUKI MORIGUCHI ${ }^{1,6}$
}

\begin{abstract}
${ }^{1}$ Post-Graduate Program in Health Sciences, Cardiology and Cardiovascular Sciences, Universidade Federal do Rio Grande do Sul (UFRGS), Hospital de Clínicas de Porto Alegre (HCPA); ${ }^{2}$ Post-Graduate Program in Genetics and Molecular Biology, HCPA/UFRGS; ${ }^{3}$ Laboratory of Genomic Medicine, Experimental Research Center/Medical Genetics Service, Hospital de Clínicas de Porto Alegre; ${ }^{4}$ Post-Graduate Program in Medicine: Medical Sciences, UFRGS/HCPA; ${ }^{5}$ Post-Graduate Program in Epidemiology, Department of Statistics, Institute of Mathematics, UFRGS; ${ }^{6}$ Coorte Núcleo Mama Porto Alegre, Hospital Moinhos de Vento, Porto Alegre; ${ }^{7}$ Hospital do Coração, São Paulo, Brazil
\end{abstract}

Received February 27, 2014; Accepted May 30, 2014

DOI: $10.3892 / \mathrm{mco} .2014 .369$

\begin{abstract}
The purpose of this study was to evaluate the association between apolipoprotein E (APOE) allelic frequency, serum lipoproteins and breast cancer (BC). We conducted a nested case-control study within a cohort including 47 cases and 165 controls. Polymerase chain reaction-restriction fragment length polymorphism analyses of the APOE polymorphism were performed. In general, participants with the genotype including alleles e 2 and e 3 tended to have lower serum triglycerides, total cholesterol and low-density lipoprotein cholesterol levels and higher high-density lipoprotein (HDL) cholesterol levels compared to participants homozygous for the e3 allele and participants heterozygous for the e3 and e 4 alleles, respectively. BC patients exhibited higher mean levels of total serum cholesterol $(\mathrm{P}=0.070)$, dietary fat intake $(\mathrm{P}=0.020)$ and dietary cholesterol intake $(\mathrm{P}=0.017)$ compared to control subjects. The allelic distribution between the two groups revealed that the presence of the e 2 allele was positively associated with the absence of $\mathrm{BC}$, whereas the e4 allele was positively associated with the $\mathrm{BC}$ case group $(\mathrm{P}=0.019)$. The distribution of the APOE genotypes was not significantly different between cases and controls $(\mathrm{P}=0.172)$. The concomitant presence of the $\mathrm{e} 2$ and $\mathrm{e} 4$ alleles was positively associated with the absence of $\mathrm{BC}$ and e4/e4 homozygosity was positively associated with $\mathrm{BC}(\mathrm{P}=0.021)$. Our findings suggested that
\end{abstract}

Correspondence to: Professor Emilio Hideyuki Moriguchi, Post-Graduate Program in Health Sciences, Cardiology and Cardiovascular Sciences, Universidade Federal do Rio Grande do Sul, Hospital de Clínicas de Porto Alegre (HCPA), 2350 Ramiro Barcelos Street, Porto Alegre, Rio Grande do Sul 90035-001, Brazil E-mail: emilio.moriguchi@gmail.com

Key words: apolipoprotein E, apolipoprotein E4, e4 allele, cardiovascular diseases, dyslipidemias
APOE polymorphism plays an important role in the development of BC, particularly when associated with higher serum triglyceride levels.

\section{Introduction}

Apolipoprotein E (APOE) is a member of the apolipoprotein gene family and plays an important role in lipid metabolism by mediating the binding of lipoprotein particles to the low-density lipoprotein (LDL) receptor and the APOE receptor (1). The genetic polymorphisms of APOE are among the most extensively investigated, particularly due to the effects of APOE on lipid profiles and the risk of coronary heart disease (2). The structural gene locus of APOE is polymorphic (3): there are three common alleles, namely e2, e3 and e4, coding for three isoforms, namely E2, E3 and E4, respectively, which produce three homozygous genotypes (E2/E2, E3/E3 and E4/E4) and three heterozygous genotypes (E2/E3, E2/E4 and E3/E4) (4). It was demonstrated that women with one or two copies of the e 4 allele and those with high concentrations of triglycerides had four times the risk of developing breast cancer (BC) compared to women with low triglyceride levels. The increase in $\mathrm{BC}$ risk may be attributed to a variety of factors, such as the effect of reduced triglyceride clearance from the plasma, resulting in constantly elevated concentrations, which may result in decreased sex hormone-binding globulin levels (5). However, the evidence remains inconclusive, as other studies reported no association between the presence of either the $\mathrm{e} 2$ or the e 4 allele and the rate of tumor cell proliferation or clinical outcome in Italian BC patients (6).

The APOE2 protein differs from the wild-type protein, APOE3, by a single amino acid change resulting in minimal receptor binding activity and reduced clearance of chylomicron remnants (7). APOE4 differs from APOE3 in that a different amino acid substitution results in faster chylomicron clearance (7). In general, compared to individuals with the e3 allele, the levels of total and LDL cholesterol tend to be 
lower in those with the 2 allele and higher in those with the e4 allele. The e 4 allele has been associated with increased risk of coronary heart disease (8) and Alzheimer's disease (9). By contrast, it was reported that there is a lower frequency of the e4 allele among patients with proximal tumors of the colon compared to that among healthy individuals (8).

Dietary fat intake has been hypothesized to be associated with BC risk based on animal studies (10), ecological studies (11) and studies on migrants from areas with low fat intake to those with high fat intake (12). An association between cholesterol intake and $\mathrm{BC}$ risk has not been established (13). The failure to identify an association between fat intake and $\mathrm{BC}$ in those studies may be due to the interindividual differences in fat consumption within populations being inadequately detected with epidemiological methods (14) and due to the measurement error that is inherent in dietary questionnaires (15). Furthermore, the assessment of the recent diet may be the wrong exposure and earlier dietary habits may be more important. In addition, the intercountry differences may be associated with other, correlated differences in dietary intake or other exposures.

Serum lipoprotein levels have also been investigated in relation to $\mathrm{BC}$ etiology as a potential mediating effect of dietary fat on $\mathrm{BC}$ risk and as an independent risk factor. The associations between serum or plasma total cholesterol, high-density lipoprotein (HDL) cholesterol, LDL cholesterol and triglycerides have been widely investigated; however, the results have been inconsistent. Certain studies reported no adverse effect of lipoproteins $(16,17)$, whereas others reported an excess risk associated with elevated total cholesterol $(18,19)$ and triglyceride levels $(14,20,21)$ or inverse associations with total cholesterol (19) or HDL cholesterol levels $(20,21)$.

The association between APOE and BC has not been definitively established and the results are often conflicting. Despite the availability of data associating the frequency of APOE genotypes with cancer in general, the number of studies investigating the association between BC and APOE is currently limited, whereas this association in the Brazilian population has yet to be investigated. In this context and since APOE is known to modify the association between dietary intake and blood lipid levels, we aimed to evaluate the association between APOE allelic frequency, serum lipoproteins and $\mathrm{BC}$ risk in a sample of women from Porto Alegre, Brazil.

\section{Subjects and methods}

Study design and participant recruitment. This was a nested case-control study within a cohort. Our sample included $\mathrm{BC}$ patients and heathy controls recruited from the Porto Alegre Breast Health Intervention Cohort. In April, 2004, a large population-based cohort study was initiated in Porto Alegre, the capital of the southern Brazilian state of Rio Grande do Sul. The cohort aimed to collect demographic, epidemiological and risk factor data from a large sample of females aged $\geq 15$ years and test a model for community-based BC screening for women aged 40-69 years, as described elsewhere $(22,23)$.

Considering that the average frequency of the e 4 allele previously described in a sample of Taiwanese women without BC was $5.4 \%$ (24), with a power of $80 \%$, a confidence interval (CI) set at $95 \%$ and a case:control ratio of 1:3, we estimated an ideal sample size of 52 cases and 156 controls. The case group included patients with carcinoma in situ or invasive tumor histologically confirmed.

Study variables. Demographic and clinical information screening data were obtained through chart review. The study variables included age, age at menarche, age at first pregnancy, period of exclusive breast feeding (months), number of children, menopausal status and medications used. The body mass index $(\mathrm{BMI})$ was calculated as weight $(\mathrm{kg})$ divided by height squared $\left(\mathrm{m}^{2}\right)$. The abdominal circumference (AC) was measured with a measuring tape at midway between the lower rib and the iliac crest.

Biochemical analyses were performed on venous blood obtained following a recommended 12-h overnight fasting. The samples were collected in tubes without anticoagulants for the quantification of lipids and glucose. For result analyses, the following normal values were considered: plasma total cholesterol $<200 \mathrm{mg} / \mathrm{dl}$, plasma triglycerides $<150 \mathrm{mg} / \mathrm{dl}$; plasma HDL >50 mg/dl; plasma LDL-C <160 mg/dl (25).

Molecular analyses. Peripheral blood samples from all the patients were collected in EDTA tubes. DNA was extracted with the standard Illustra Blood genomicPrep Mini Spin kit (GE Healthcare, Piscataway, NJ, USA). APOE genotyping was performed by polymerase chain reaction (PCR)-restriction fragment length polymorphism as described by Hixson and Vernier (26). Briefly, the 244-bp amplicon obtained by PCR was enzyme-restricted using $\mathrm{HhaI}$ and resulted in fragments of different sizes, which were resolved by polyacrylamide gel electrophoresis as follows: i) fragments of 91 and 83 bp for genotype E2E2; ii) fragments of 91, 48 and 35 bp for genotype E3E3; and (iii) fragments of 72, 48 and 35 bp for genotype E4E4. Throughout the manuscript we collectively refer to the genotypes E3E3 as APOE3, E2E3 and E2E4 as APOE2 and E3E4 and E4E4 as APOE4.

Statistical analyses. SPSS software, version 18.0 (SPSS Inc., Chicago, IL, USA) was used for data handling and statistical analyses. To evaluate the differences in demographic, anthropometric, lifestyle, gynecological and obstetrical characteristics between the two groups, we used the Student's t-test for normally distributed variables, the Mann-Whitney test for non-parametric variables without a normal distribution and the Chi-square test for categorical variables. Logistic regression analysis was used to calculate the odds ratios (ORs) and 95\% CIs for the APOE polymorphism. The ORs were adjusted by the dietary consumption of proteins, fats, carbohydrates and cholesterol. The variables of age, age at menarche and number of children were not included, as the P-values were not $<0.20$ following logistic regression analyses.

Ethics. This study was approved by the Institutional Research and Ethics Committees of the participating institutions (Clinics Hospital of Porto Alegre protocols: 05-182 and 08/070; Moinhos de Vento Hospital protocol 2008/86). All the participants provided written informed consent prior to their inclusion in the study. 
Table I. Clinical and demographic characteristics of breast cancer patients and healthy controls.

\begin{tabular}{|c|c|c|c|c|c|}
\hline \multirow[b]{2}{*}{ Characteristics } & \multicolumn{2}{|c|}{ Cases $(n=47)$} & \multicolumn{2}{|c|}{ Controls ( $\mathrm{n}=165)$} & \multirow[b]{2}{*}{ P-value } \\
\hline & No. $(\%)$ & Median (IIQ or SD) & No. $(\%)$ & Median (IIQ or SD) & \\
\hline Age $\left(\right.$ years) ${ }^{a}$ & & $57.6(10.6)$ & & $56.1(8.1)$ & 0.295 \\
\hline BMI $\left(\mathrm{kg} / \mathrm{m}^{2}\right)^{\mathrm{b}}$ & & $28.2(5.9)$ & & $28.9(7.2)$ & 0.206 \\
\hline Abdominal circumference $(\mathrm{cm})^{\mathrm{b}}$ & & $93.0(17.0)$ & & $94.0(17.0)$ & 0.850 \\
\hline Age at menarche (years $)^{\mathrm{b}}$ & & $13.0(3.0)$ & & $13.0(2.0)$ & 0.584 \\
\hline Age at first pregnancy (years) ${ }^{\mathrm{b}}$ & & $20.0(5.0)$ & & $22.0(8.0)$ & 0.365 \\
\hline Exclusive breast feeding (months) & & $15.0(45.0)$ & & $12.0(32.0)$ & 0.526 \\
\hline \multicolumn{6}{|l|}{ No. of children, n (\%) } \\
\hline $1-3$ & $32(68.1)$ & & $114(53.77)$ & & \\
\hline$>4$ & $15(31.9)$ & & $51(46.2)$ & & 0.730 \\
\hline Menopausal status, n (\%) & & & & & 0.434 \\
\hline Yes & $31(67.4)$ & & $102(61.1)$ & & \\
\hline Hormone therapy use, $\mathrm{n}(\%)$ & & & & & 0.179 \\
\hline Yes & $5(11.1)$ & & $33(19.8)$ & & \\
\hline Contraceptive use, n (\%) & & & & & 0.403 \\
\hline Yes & 34 (73.9) & & $133(79.6)$ & & \\
\hline
\end{tabular}

${ }^{a}$ Median and standard deviation (SD), t-test. ${ }^{b}$ Median and interquartile range (IIQ), Mann-Whitney non-parametric test and Chi-square test. BMI, body mass index.

\section{Results}

Subjects. A total of $47 \mathrm{BC}$ patients and 165 healthy controls were included in this study. The characteristics of the sample are summarized in Table I. There were no statistically significant differences between the groups regarding mean age, BMI, $\mathrm{AC}$, age at menarche, age at first pregnancy, breastfeeding, number of children, menopausal status, hormone and contraceptive use.

APOE genotype distribution. The distribution of the APOE genotypes in the total sample and by disease status is shown in Table II. Regardless of the disease status, nearly all the participants $(90.0 \%)$ carried at least one e3 allele, $34.5 \%$ carried an e4 allele and $17.5 \%$ carried an e 2 allele, which was consistent with a recent study based on Caucasian women (27). Table II shows the mean serum lipoprotein levels by APOE genotype. In general, participants with the genotype including alleles e 2 and e 3 tended to have lower serum triglycerides, total cholesterol and LDL cholesterol levels and higher HDL cholesterol levels compared to participants homozygous for allele 3 and those heterozygous for alleles e3 and e4, respectively. This pattern was more apparent for the total sample and the BC cases and less apparent for the controls. Only one woman in the control group was homozygous for allele e4 and exhibited the highest serum levels of triglycerides, LDL and HDL.

Serum lipoproteins and dietary fat intake. There were differences between the cases and controls regarding the mean levels of total serum cholesterol $(\mathrm{P}=0.070)$, dietary fat intake $(\mathrm{P}=0.020)$ and dietary cholesterol intake $(\mathrm{P}=0.017)$. There were no significant differences in serum HDL, LDL and triglyceride levels between the groups, as shown in Table III.

Allele and genotype distribution in BC patients and controls. The analysis of the allelic distribution between the two groups (Table IV) revealed that the presence of the e 2 allele was positively associated with the absence of $\mathrm{BC}$, whereas the $\mathrm{e} 4$ allele was positively associated with the $\mathrm{BC}$ case group $(\mathrm{P}=0.019)$. The distribution of the APOE genotypes, however, exhibited no significant difference between the cases and the controls $(\mathrm{P}=0.172)$. Moreover, the concomitant presence of the 2 and e4 alleles was positively associated with the absence of $\mathrm{BC}$ and e4/e4 homozygosity was positively associated with the presence of $\mathrm{BC}(\mathrm{P}=0.021)$, suggesting a dominant negative effect of the e 2 over the e 4 allele.

\section{Discussion}

To the best of our knowledge, this is the first study to investigate the association between the APOE genotype, serum lipoprotein levels and BC risk in Brazilian women. In the total sample, we observed that women who had at least one e4 allele presented with higher triglyceride levels compared to those with an e2 allele (Table II). Previous studies reported an increased risk of $\mathrm{BC}$ in association with elevated triglyceride levels $(14,20,21)$ and the possibility of a number of biological mechanisms underlying this association has been investigated. The increase in the $\mathrm{BC}$ risk may be due to a variety of factors, 
Table II. Mean serum lipoprotein levels by APOE genotype in breast cancer patients and healthy controls ${ }^{\mathrm{a}}$.

\begin{tabular}{|c|c|c|c|c|c|}
\hline APOE genotype & No. $(\%)$ & $\begin{array}{c}\text { Total cholesterol } \\
\text { (mg/dl) } \\
\text { Mean (SD) }\end{array}$ & $\begin{array}{l}\text { HDL cholesterol } \\
\text { (mg/dl) } \\
\text { Mean (SD) }\end{array}$ & $\begin{array}{c}\text { LDL cholesterol }^{\mathrm{b}} \\
(\mathrm{mg} / \mathrm{dl}) \\
\text { Mean }(\mathrm{SD})\end{array}$ & $\begin{array}{c}\text { Triglycerides } \\
(\mathrm{mg} / \mathrm{dl}) \\
\text { Mean (SD) }\end{array}$ \\
\hline \multicolumn{6}{|c|}{ Total sample $(n=212)$} \\
\hline $2 / 3$ & $20(9.4)$ & $210.3(47.9)$ & $56.0(21.1)$ & $121.7(44.9)$ & $162.7(103.3)$ \\
\hline $2 / 4$ & $17(8.1)$ & $185.0(32.7)$ & $53.6(11.2)$ & $100.7(31.3)$ & $153.2(83.1)$ \\
\hline $3 / 3$ & $119(56.1)$ & $201.3(45.8)$ & $51.4(14.6)$ & $116.7(44.8)$ & $165.8(84.0)$ \\
\hline $3 / 4$ & $52(24.5)$ & $216.9(52.4)$ & $50.1(13.8)$ & $128.9(53.2)$ & $189.2(155.2)$ \\
\hline $4 / 4$ & $4(1.9)$ & $187.2(22.1)$ & $48.5(11.1)$ & $90.2(56.3)$ & $242.7(123.9)$ \\
\hline \multicolumn{6}{|l|}{ Cases $(n=47)$} \\
\hline $2 / 3$ & $4(8.5)$ & $253.5(72.5)$ & $51.0(14.1)$ & $166.3(56.4)$ & $181.0(159.3)$ \\
\hline $3 / 3$ & $28(59.6)$ & $189.9(55.2)$ & $48.4(12.1)$ & $109.7(51.4)$ & $159.1(61.8)$ \\
\hline $3 / 4$ & $12(25.5)$ & $194.7(50.3)$ & $50.2(15.2)$ & $106.5(56.4)$ & $190.3(241.1)$ \\
\hline $4 / 4$ & $3(6.4)$ & $195.3(18.4)$ & $43.7(6.6)$ & $114.2(35.9)$ & $187.3(67.9)$ \\
\hline \multicolumn{6}{|l|}{ Controls $(n=165)$} \\
\hline $2 / 3$ & $16(9.7)$ & $199.5(35.2)$ & $57.2(22.7)$ & $110.6(35.4)$ & $158.1(91.3)$ \\
\hline $2 / 4$ & $17(10.3)$ & $185.0(32.6)$ & $53.6(11.1)$ & $100.7(31.3)$ & $153.2(83.1)$ \\
\hline $3 / 3$ & $91(55.2)$ & $204.8(42.3)$ & $52.3(15.2)$ & $118.9(42.6)$ & $167.8(89.9)$ \\
\hline $3 / 4$ & $40(24.2)$ & $223.6(51.8)$ & $50.1(13.6)$ & $135.7(50.9)$ & $188.8(122.8)$ \\
\hline $4 / 4$ & $1(0.6)$ & 163 & 63 & 180.2 & 409.0 \\
\hline
\end{tabular}

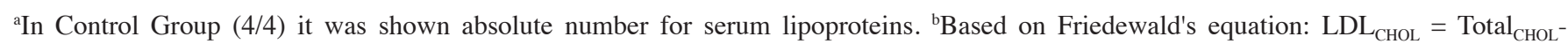
$\mathrm{HDL}_{\mathrm{CHOL}^{-}}(\mathrm{TG} / 5)$. APOE, apolipoprotein E; LDL, low-density lipoprotein; HDL, high-density lipoprotein; TG, triglycerides; SD, standard deviation.

Table III. Comparison of serum lipoprotein levels and dietary fat intake between breast cancer patients and healthy controls.

\begin{tabular}{|c|c|c|c|}
\hline Variables & $\begin{array}{c}\text { Cases }(n=47) \\
\text { Mean }(25-75 \%)\end{array}$ & $\begin{array}{l}\text { Controls }(n=165) \\
\text { Mean }(25-75 \%)\end{array}$ & P-value \\
\hline Serum cholesterol (mg/dl) & $193.0(165.0-217.0)$ & $209.0(172.0-230.5)$ & 0.070 \\
\hline Serum HDL (mg/dl) & $47.0(40.0-55.0)$ & $50.0(42.0-61.0)$ & 0.166 \\
\hline Serum LDL $(\mathrm{mg} / \mathrm{dl})^{\mathrm{a}}$ & $107.6(79.8-140.0)$ & $121.2(92.7-147.0)$ & 0.154 \\
\hline Serum triglycerides (mg/dl) & $151.0(105.0-200.0)$ & $150.0(101.5-217.5)$ & 0.656 \\
\hline Dietary fat intake (g/day) & $66.1(49.4-83.0)$ & $56.8(45.3-67.1)$ & 0.020 \\
\hline Dietary cholesterol intake (mg/day) & $254.6(197.5-325.4)$ & $214.5(156.8-281.2)$ & 0.017 \\
\hline
\end{tabular}

${ }^{\mathrm{a}}$ Based on Friedewald's equation: $\mathrm{LDL}_{\mathrm{CHOL}}=\mathrm{Total}_{\mathrm{CHOL}}-\mathrm{HDL}_{\mathrm{CHOL}}-(\mathrm{TG} / 5)$. LDL, low-density lipoprotein; HDL, high-density lipoprotein; TG, triglycerides.

such as the effect of reduced triglyceride clearance from the plasma, resulting in continuously elevated concentrations, which may result in decreased sex hormone-binding globulin levels (28). It was previously reported that e4 allele carriers may, in a dose-dependent manner, exhibit decreased ability for effective repair at the cellular level following noxious injury (3). Such an injury may also be caused by environmental factors, such as fat and cholesterol intake, alcohol consumption, stress and occupational exposures (1). This inability for repair following injury may subsequently affect serum lipids in the form of reduced triglyceride clearance from the plasma. Consequently, the serum triglyceride levels will increase, since free fatty acids and serum triglycerides routinely increase in response to trauma or during injury at the cellular level $(3,4)$.

The allelic frequency, presented in Table IV, was generally similar to that reported by other studies. However, in our study, the e4 allele frequency in both the control (17.9\%) and case groups (19.1\%), was marginally higher compared to that estimated in other studies from other countries, including Brazil (Table V). A possible explanation for this difference may be the variability in ethnicities, which is characteristic of the Brazilian population. Certain studies reported that the frequency of the e 4 allele may vary with different regional geography $(3,27)$. Certain studies suggested that the e 4 allele is 
Table IV. Allele and genotype distribution in breast cancer patients and healthy controls.

\begin{tabular}{lcccc}
\hline $\begin{array}{l}\text { Allele/ } \\
\text { genotype }\end{array}$ & $\begin{array}{c}\text { Cases } \\
(\mathrm{n}=47)\end{array}$ & $\begin{array}{c}\text { Controls } \\
(\mathrm{n}=165)\end{array}$ & $\begin{array}{c}\text { Total } \\
(\mathrm{n}=212)\end{array}$ & \\
\hline Alleles & & No. $(\%)$ & No. $(\%)$ & P-value $^{\mathrm{a}}$ \\
e2 & $4(4.2)$ & $33(10)$ & $37(8.7)$ & 0.019 \\
e3 & $72(76.7)$ & $238(72.1)$ & $310(73.1)$ & \\
e4 & $18(19.1)$ & $59(17.9)$ & $77(18.2)$ & \\
Genotypes & & & & 0.172 \\
e2 carriers & $4(8.5)$ & $33(20)$ & $37(17.4)$ & \\
e3 carriers & $28(59.6)$ & $91(55.1)$ & $119(56.1)$ & \\
e4 carriers & $15(31.9)$ & $41(24.9)$ & $56(26.5)$ & \\
\hline
\end{tabular}

${ }^{a}$ Chi-square test. The e 2 carriers included the genotypes e2/e2, e2/e3 and e2/e4; the e 3 carriers included e3/e3; the e 4 carriers included e3/e4 and e4/e4. APOE, apolipoprotein E.

more prevalent in African-Americans compared to Hispanics or non-Hispanic whites (1) and the frequency of this allele was found to be inversely correlated with human ageing (1).

Furthermore, we identified a positive association between the presence of the e 4 allele and $\mathrm{BC}(\mathrm{P}=0.019)$, whereas the presence of the $\mathrm{e} 2$ allele was positively associated with the absence of $\mathrm{BC}$. The concomitant presence of the $\mathrm{e} 2$ and e4 alleles was positively associated with absence of $\mathrm{BC}$ and e4/e4 homozygosity was positively associated with BC $(\mathrm{P}=0.021)$, suggesting a dominant negative effect of the e 2 over the e 4 allele. Evidence suggested that the e 4 allele may be accompanied by less effective repair ability following DNA damage, contributing to carcinogenesis (3). The poor repair capacity associated with the e 4 allele may also be due to the actual structure and function of APOE in lipid transport and cellular metabolism and differentiation $(3,4)$. For all the lipoprotein subfractions, the e 4 allele is catabolized three times faster compared to the e 2 allele in heterozygous e2/e4 subjects, suggesting that these alleles may have distinct metabolic pathways (3).

Several methodological issues require consideration in interpreting our findings. Sample size was a limitation in this study, similar to other molecular epidemiological studies (5). Even having obtained a marginally higher e4 allelic frequency compared to that reported by other studies, the allelic frequencies of APOE were consistent with previous evidence (27). It is possible that the association between APOE genotype, triglycerides and $\mathrm{BC}$ risk may be a result of sampling variation. Another important point is that there is always a possibility that the disease process or treatment may have affected the measurements in case-control studies. It was previously hypothesized that blood lipid levels are affected by surgery as part of the metabolic and neuroendocrine response to the procedure (35). In addition, there is evidence that the blood lipid levels may be affected by chemotherapy and tamoxifen treatment (36). In this study, the $\mathrm{BC}$ patients exhibited lower cholesterol serum levels compared to controls $(\mathrm{P}=0.070)$,
Table V. Comparison of the APOE allele frequency in women without $\mathrm{BC}$ (healty controls) in this study compared to that in other populations worldwide.

\begin{tabular}{lrrrr}
\hline & & \multicolumn{3}{c}{ APOE alleles (\%) } \\
\cline { 3 - 5 } Authors/(Refs.) & No. & e2 & e3 & e4 \\
\hline Present study & 165 & 10.0 & 72.1 & 17.9 \\
Ojopi et al (29) & 258 & 6.7 & 77.3 & 15.8 \\
Chang et al (30) & 232 & 9.7 & 75.2 & 15.1 \\
Brandão et al (31) & 118 & 5.1 & 81.4 & 13.5 \\
Feng et al (32) & 506 & 9.5 & 79.3 & 11.1 \\
Schwanke et al (33) & 70 & 5.0 & 84.0 & 11.0 \\
Souza et al (34) & 200 & 5.6 & 86.0 & 9.0 \\
\hline
\end{tabular}

APOE, apolipoprotein E.

although the $\mathrm{BC}$ group reported higher fat and cholesterol dietary intake $(\mathrm{P}=0.020$ and $\mathrm{P}=0.017$, respectively), supporting this hypothesis.

It should be noted that the State of Rio Grande do Sul (RS, the southernmost state in Brazil) has one of the highest BC incidence rates in the country, with an estimated rate of 87 new cases per 100,000 women in 2014, a number comparable to the USA and North Europe. The State's capital, Porto Alegre, where this study was conducted, has an even higher BC incidence rate, with 146 new cases per 100,000 women projected for 2014 (37). Furthermore, in RS there is a high prevalence of cardiovascular risk factors, such as hypertension (38), obesity $(39,40)$, smoking (39) and sedentary lifestyle $(39,40)$, mainly among women. In this context, it is possible that the high e4 allele frequency evidenced in our study contributes not only to the high incidence rates of $\mathrm{BC}$ in Porto Alegre, but to the increment in the incidence of cardiovascular disease, as already reported in the literature (41).

The aim of this study was in to verify the frequency of APOE polymorphisms in a sample of women residing in an area with a high incidence of $\mathrm{BC}$ and cardiovascular disease. In view of the significant opposite impacts of the e 4 and e 2 alleles on the risk of $\mathrm{BC}$, it is likely that the investigated population is more susceptible not only to $\mathrm{BC}$, but also to cardiovascular diseases. As this is the first study to verify the association of APOE with BC risk in a sample of Brazilian women, the results of our study should be replicated in monoethnic and in ethnically diverse populations. The gene expression profiles in specific types of human tumors, including the expression profiles of APOE in BC, may contribute to our better understanding of the variations in the genotype of those individuals at higher risk for this disease. Such analyses may also be used to enhance the understanding of additional biological and environmental factors and may identify markers of more aggressive cells in different types of human BC.

The emphasis on achievable cancer prevention strategies with a focus on modifiable lifestyle factors is imperative, since the appropriate role of APOE genotyping for BC risk remains ambiguous, as neither the presence nor the absence of an e4 allele provides diagnostic certainty of BC susceptibility (28). 
Given that there is also conflicting evidence as to whether the presence or the absence of an e4 allele confers an increased risk for BC, the diagnostic use of APOE genotyping for cancer or any other chronic disease outside of the research setting may be premature.

In conclusion, our findings suggested that APOE polymorphisms play an important role in the development of $\mathrm{BC}$, particularly when associated with higher serum triglyceride levels. Overall, the APOE genotype was not found to be associated with the risk of $\mathrm{BC}$, but we identified a positive association between the 4 allele and $\mathrm{BC}$ risk, whereas the e2 allele appeared to be protective against the disease. As the first Brazilian study to investigate the association between APOE genotype, serum lipoprotein levels and BC risk, further investigation is required to determine whether our results are replicated in monoethnic and ethnically diverse populations.

\section{Acknowledgements}

We would like to thank all the patients who participated in our study. We would also like to thank Dr Osvaldo Artigalás for his contribution. This study is part of the Project 'Moinhos Restinga Extremo Sul' sponsored by the Brazilian Ministry of Health to support the development of the Brazilian public health system (grant code 06/2008, November 17, 2008). We also received financial support from FIPE/Hospital de Clínicas of Porto Alegre, number of project 08-070.

\section{References}

1. Beisiegel U, Weber W, Ihrke G, et al: The LDL-receptor related protein, LPR, is an apolipoprotein E-binding protein. Nature 341 $162-170,1989$.

2. Eichner JE, Dunn T, Perveen G, Thompson DM, Stewart KE and Stroehla BC: Apolipoprotein E polymorphism and cardiovascular disease: a HuGE review. Am J Epidemiol 155: 487-495, 2002.

3. Mahley RW and Rall SC Jr: Apolipoprotein E: Far more than a lipid transport protein. Annu Rev Genomics Hum Gene 1: 507-537, 2000

4. Hartman RE, Laurer H, Longhi L, Bales KR, Paul SM, McIntosh TK and Holtzman DM: Apolipoprotein E4 influences amyloid deposition but not cell loss after traumatic brain injury in a mouse model of Alzheimer's disease. J Neurosci 22 10083-10087, 2002.

5. Moysich KB, Freudenheim JL, Baker JA, et al: Apolipoprotein E genetic polymorphism, serum lipoproteins, and breast cancer risk. Mol Carcinog 27: 2-9, 2000.

6. Zunarelli E, Nicoll JA, Migaldi M and Trentini GP: Apolipoprotein $\mathrm{E}$ polymorphism and breast carcinoma: correlation with cell proliferation indices and clinical outcome. Breast Cancer Res Treat 63: 193-198, 2000.

7. Breslow JL: Genetic basis of lipoprotein disorders. J Clin Invest 84: 373-380, 1989

8. Kervinen K, Södervik H, Mäkelä J, Lehtola J, Niemi M, Kairaluoma MI and Kesäniemi YA: Is the development of adenoma and carcinoma in proximal colon related to apolipoprotein E genotype? Gastroenerology 110: 1785-1790, 1996.

9. Kuusisto J, Koivisto K, Kervinen K, et al: Association of apolipoprotein phenotypes with late onset Alzheimer's disease: population based study. BMJ 309: 636-638, 1994.

10. Cave WT Jr: Dietary fat effects on animal models of breast cancer. In: Diet and Breast Cancer. Weisburger EK (ed). Plenum Press, New York, pp 47-58, 1994.

11. Caroll KK, Braden LM, Bell JM and Kalamegham R: Fat and cancer. Cancer 58: 1818-1825, 1986.

12. Dunn JE: Breast cancer among American Japanese in the San Francisco bay area. Natl Canc Inst Monogr 47: 157-160, 1977.
13. Willett WC, Hunter DJ, Stampfer MJ, et al: Dietary fat and fiber in relation to risk of breast cancer. An 8-year follow up. JAMA 268: 2037-2044, 1992.

14. Goodwin PJ and Boyd NF: Critical appraisal of the evidence that dietary fat intake is related to breast cancer in humans. J Natl Cancer Inst 79: 473-485, 1987.

15. Bingham SA, Gill C, Welch A, et al: Comparison of dietary assessment methods in nutritional epidemiology: weighted records v. $24 \mathrm{~h}$ recalls, food-frequency questionnaries and estimated-diet records. Br J Nut 72: 619-643, 1994.

16. Törnberg SA, Holm LE and Carstensen JM: Breast cancer risk in relation to serum cholesterol, serum beta-lipoprotein, height, weight, and blood pressure. Acta Oncol 27: 31-37, 1988.

17. Vatten LJ and Foss OP: Total serum cholesterol and triglycerides and risk of breast cancer: a prospective study of 24,329 Norwegian women. Cancer Res 50: 2341-2346, 1990.

18. Gerber M, Cavallo F, Marubini E, et al: Liposoluble vitamins and lipid parameters in breast cancer. A joint study in northern Italy and southern France. Int J Cancer 42: 489-494, 1988.

19. Vatten LJ, Foss OP and Kvinnsland S: Overall survival of breast cancer patients in relation to preclinically determined total serum cholesterol, body mass index, height and cigarette smoking: a population-based study. Eur J Cancer 27: 641-646, 1991.

20. Høyer AP and Engholm G: Serum lipids and breast cancer risk: a cohort study of 5,207 Danish women. Cancer Causes Control 3: 403-480, 1992.

21. Kökoğlu E, Karaarslan I, Karaarslan HM and Baloglu H: Alterations of serum lipids and lipoproteins in breast cancer. Cancer Lett 82: 175-178, 1994.

22. Giacomazzi J, Aguiar E, Palmero EI, et al: Breast cancer screening in 10.000 women of an underserved population in South Brazil: The NMAMAPOA cohort. J Clin Oncol 23: 1020-1027, 2005

23. Caleffi M, Ribeiro RA, Duarte Filho DL, et al: A model to optimize public health care and downstage breast cancer in limited-resource populations in southern Brazil. (Porto Alegre Breast Health Intervention Cohort). BMC Public Health 9: 83, 2009.

24. Chang SJ, Hou MF, Tsai SM, Kao JT, Wu SH, Hou LA and Tsai LY: Association between the apolipoprotein E genotypes and breast cancer patients in Taiwanese. Breast Cancer Res Treat 98: 109-113, 2006

25. Sposito AC, Caramelli B, Fonseca FA, et al; Brazilian Society of Cardiology: IV Brazilian guideline for dyslipidemia and atherosclerosis prevention: Department of Atherosclerosis of Brazilian Society of Cardiology. Arq Bras Cardiol 88: 2-19, 2007 (In Portuguese).

26. Hixson JE and Vernier DT: Restriction isotyping of human apolipoprotein E by gene amplification and cleavage with HhaI. J Lipid Res 31: 545-548, 1990.

27. Howard BV, Gidding SS and Liu K: Association of apolipoprotein E phenotype with plasma lipoproteins in African-American and white young adults. The CARDIA Study. Coronary Artery Risk Development in Young Adults. Am J Epidemiol 48: 859-868, 1998.

28. Niemi M, Kervinen K, Kiviniemi H, et al: Apolipoprotein $\mathrm{E}$ phenotype, cholesterol and breast and prostate cancer. J Epidemiol Community Health 54: 938-939, 2000.

29. Ojopi EPB, Bertoncini AB and Dias Neto E: Apolipoproteína E e a doença de Alzheimer. Rev Psiq Clín 31: 26-33, 2004.

30. Chang NW, Chen DR, Wu CT, Aouizerat BE, Chen FN, Hung SJ, Wang SH, Wei MF and Chang CS: Influences of apolipoprotein E polymorphism on the risk for breast cancer and HER2/neu status in Taiwan. Breast Cancer Res Treat 90: 257-261, 2005.

31. Brandão AC, Pinheiro SP Jr, Pinhel MA, et al: Polimorfismo genético da apolipoproteína $\mathrm{E}$ na doença arterial periférica. J Vasc Br 3: 317-322, 2004.

32. Feng J, Xiang L, Wan G, et al: Is APOE E a favorable factor for the longevity: an association study in Chinese population. J Genet 90: 343-347, 2011.

33. Schwanke CH, da Cruz IB, Leal NF, Scheibe R, Moriguchi Y, Moriguchi EH: Analysis of the association between apolipoprotein E polymorphism and cardiovascular risk factors in an elderly population with longevity. Arq Bras Cardiol 78: 561-570, 2002 (In English, Portuguese).

34. Souza D, Campos BF, Arruda EF, Yamamoto LJ, Trindade DM and Tognola WA: Influence of the polymorphism of apolipoprotein $\mathrm{E}$ in cerebral vascular disease. Arq Neuropsiquiatr 61: 7-13, 2003.

35. McNamara JJ, Molot M, Dunn R, Burran EL and Stremple JF: Lipid metabolism after trauma. Role in the pathogenesis of fat embolism. J Thoracic Cardiovasc Surg 63: 968-972, 1972. 
36. Morales M, Santana N, Soria A, Soria A, Mosquera A, Ordovás J, Nóvoa J, Betancor P, Valerón PF, Díaz-Chico B and Chirino R: Effects of tamoxifen on serum lipid and apolipoprotein levels in postmenopausal patients with breast cancer. Breast Cancer Res Treat 49: 265-270, 1996.

37. Instituto Nacional de Câncer José Alencar Gomes da Silva. Coordenação de Prevenção e Vigilância Estimativa 2014: Incidência de Câncer no Brasil/Instituto Nacional de Câncer José Alencar Gomes da Silva, Coordenação de Prevenção e Vigilância Rio de Janeiro: INCA, p 92, 2014.

38. Fuchs FD: Systemic arterial hypertension. Epidemiology and risk factors. Arq Bras Cardiol 63: 443-444, 1994 (In Portuguese).
39. Duncan BB, Schimidt MI, Polanczyk CA, Hormrich CS, Rosa RS and Achutti AC: Risk factors for non-communicable diseases in a metropolitan area in the south of Brazil. Prevalence and simultaneity. Rev Saude Publica 27: 43-48, 1993 (In Portuguese).

40. Gus I, Fischmann A and Medina C: Prevalência dos fatores de risco da doença arterial coronariana no Estado do Rio Grande do Sul. Arq Bras Cardiol 78: 478-483, 2002 (In Portuguese).

41. Davignon J, Gregg RE and Sing CF: Apolipoprotein E polymorphism and atherosclerosis. Arterioscler Thromb Vasc Biol 8: 1-21, 1988. 